\title{
Immune cell profiles in synovial fluid after anterior cruciate ligament and meniscus injuries
}

\author{
Sophia Y. Kim-Wang 1,2, Abigail G. Holt², Alyssa M. McGowan³, Stephanie T. Danyluk², Adam P. Goode², \\ Brian C. Lau², Alison P. Toth², Jocelyn R. Wittstein², Louis E. DeFrate ${ }^{1,2,4^{*}}$, John S. Yi ${ }^{3+}$ and Amy L. McNulty ${ }^{2,5+}$
}

\begin{abstract}
Background: Anterior cruciate ligament $(\mathrm{ACL})$ and meniscus tears are common knee injuries. Despite the high rate of post-traumatic osteoarthritis (PTOA) following these injuries, the contributing factors remain unclear. In this study, we characterized the immune cell profiles of normal and injured joints at the time of ACL and meniscal surgeries.

Methods: Twenty-nine patients (14 meniscus-injured and $15 \mathrm{ACL}$-injured) undergoing $\mathrm{ACL}$ and/or meniscus surgery but with a normal contralateral knee were recruited. During surgery, synovial fluid was aspirated from both normal and injured knees. Synovial fluid cells were pelleted, washed, and stained with an antibody cocktail consisting of fluorescent antibodies for cell surface proteins. Analysis of immune cells in the synovial fluid was performed by polychromatic flow cytometry. A broad spectrum immune cell panel was used in the first 10 subjects. Based on these results, a T cell-specific panel was used in the subsequent 19 subjects.

Results: Using the broad spectrum immune cell panel, we detected significantly more total viable cells and CD3 T cells in the injured compared to the paired normal knees. In addition, there were significantly more injured knees with T cells above a 500-cell threshold. Within the injured knees, CD4 and CD8 T cells were able to be differentiated into subsets. The frequency of total CD4 T cells was significantly different among injury types, but no statistical differences were detected among CD4 and CD8 T cell subsets by injury type.

Conclusions: Our findings provide foundational data showing that $A C L$ and meniscus injuries induce an immune cell-rich microenvironment that consists primarily of T cells with multiple T helper phenotypes. Future studies investigating the relationship between immune cells and joint degeneration may provide an enhanced understanding of the pathophysiology of PTOA following joint injury.
\end{abstract}

Keywords: Monocytes, Macrophages, Cartilage, B cells

\section{Background}

Anterior cruciate ligament (ACL) ruptures and meniscal tears are common among athletes, and frequently occur in the general population [1]. In the USA, over 400,000

\footnotetext{
*Correspondence: lou.defrate@duke.edu

†John S. Yi and Amy L. McNulty contributed equally to this work.

${ }^{4}$ Department of Mechanical Engineering and Materials Science, Duke University, Durham, NC, USA

Full list of author information is available at the end of the article
}

ACL injuries occur annually [2], and more than 500,000 meniscus surgeries were performed in 2014 [3]. Moreover, the long-term sequelae of both ACL and meniscal injuries include pain, joint instability, and post-traumatic osteoarthritis (PTOA) in approximately $50 \%$ of patients $[1,4-7]$.

Despite the high rate of PTOA following joint injury, the factors that contribute to PTOA development remain unclear. Several studies have investigated altered knee original author(s) and the source, provide a link to the Creative Commons licence, and indicate if changes were made. The images or other third party material in this article are included in the article's Creative Commons licence, unless indicated otherwise in a credit line to the material. If material is not included in the article's Creative Commons licence and your intended use is not permitted by statutory regulation or exceeds the permitted use, you will need to obtain permission directly from the copyright holder. To view a copy of this licence, visit http://creativecommons.org/licenses/by/4.0/. The Creative Commons Public Domain Dedication waiver (http://creativeco mmons.org/publicdomain/zero/1.0/) applies to the data made available in this article, unless otherwise stated in a credit line to the data. 
biomechanics after ACL [8-13] and meniscus injuries [14-18], suggesting possible associations with PTOA. Other studies suggest that biological changes [19-24] that occur within the joint following injury may play a role in PTOA development as well. Nonetheless, there is little data on the biochemical and cellular environment of the joint following injury.

A few studies have measured biochemical and gene expression changes following joint injury. In the synovial fluid of ACL-injured patients, cytokines and catabolic biomarkers, including interleukin (IL)- $1 \alpha$, IL-1 $\beta$, IL-6, IL-8, lubricin, tumor necrosis factor (TNF)- $\alpha$, matrix metalloproteinases (MMPs), and cartilage oligomeric matrix protein (COMP), are increased in comparison to concentrations found in the synovial fluid of healthy, uninjured subjects [19-21, 25-27]. Among meniscusinjured subjects, increases in prostaglandin E2 (PGE2), MMP activity, MMP-3, IL-6, monocyte chemotactic protein-1, and macrophage inhibitory protein (MIP)- $1 \beta$ have been detected in the synovial fluid of injured joints $[16$, $20,23,28]$. This work has identified cytokines, catabolic biomarkers, and chemokines that are altered in injured joints and may contribute to PTOA development. However, the specific cell types in the synovial fluid that mediate the production of cytokines and chemokines have not been studied in ACL and meniscus-injured patients.

Only a few studies have evaluated cell types that are altered following joint injury in animal models. Specifically, recent animal models have shown that macrophages may be involved in the progression of PTOA after meniscus injury $[29,30]$. In addition, several studies have evaluated immune cell profiles in patients with osteoarthritis (OA) and rheumatoid arthritis (RA). In patients diagnosed with primary OA, studies have shown an increased presence of activated macrophages and $\mathrm{T}$ cells with a higher $\mathrm{CD} 4 / \mathrm{CD} 8$ ratio of $\mathrm{T}$ cells in the serum, synovial fluid, and synovial tissues [22, 31-35]. RA has also been well-studied with regard to subsets of $\mathrm{T}$ cells, demonstrating higher percentages of $\mathrm{CD} 4 \mathrm{~T}$ cells in the peripheral blood and synovial membrane compared to OA and control subjects [33, 36-38]. However, there is a lack of data on immune cell profiles in the synovial fluid of joints with ACL or meniscal injuries. Therefore, in this pilot study, we aimed (1) to determine which immune cell subsets were present in the synovial fluid following joint injury, and based on this profile (2) to identify the specific CD4 and CD8 $\mathrm{T}$ cell subset(s) that migrate to the injured synovial fluid.

\section{Methods}

\section{Inclusion criteria}

All study procedures and protocols were approved by the Institutional Review Board at Duke University School of Medicine. Patients undergoing ACL reconstruction and/or meniscus repair or meniscectomy were enrolled in the study. The following inclusion criteria were also used: minimum of 12 years of age; BMI between 18.5 and $30.0 \mathrm{~kg} / \mathrm{m}^{2}$; no history of diagnosed arthritis; and a nonoperative contralateral (normal) knee with no history of knee injury or surgery. A total of 29 subjects (14 meniscus-injured and $15 \mathrm{ACL}$-injured) that met the inclusion criteria were consented. Of the $15 \mathrm{ACL}$-injured, 5 had a concomitant meniscus injury, which will be referred to as "ACL+meniscus."

\section{Synovial fluid collection and cell isolation}

All study activities occurred on the day of surgery. In the operating room prior to incision, synovial fluid was aspirated from both the injured and normal knees. If necessary to obtain fluid, the surgeon lavaged the joint with 1-20 $\mathrm{mL}$ of normal saline. Lavage was necessary in 28 out of 29 normal knees and 5 out of 29 injured knees. Once aspirated, the synovial fluid was transferred to 15 $\mathrm{mL}$ conical tubes containing protease inhibitor (Millipore Sigma, Burlington, MA) and placed on ice. Tubes were spun at $350 \mathrm{~g}$ for $10 \mathrm{~min}$ at $4{ }^{\circ} \mathrm{C}$ to pellet the cells. The synovial fluid supernatant was removed and frozen. Next, the entire cell pellet was resuspended with gentle vortexing and the red blood cells were lysed by adding lysing solution (BD Biosciences, San Jose, CA) for $3 \mathrm{~min}$. Then, the cells were centrifuged and resuspended for cell surface staining.

\section{Flow cytometry}

Analysis of immune cells in the synovial fluid was performed by polychromatic flow cytometry (PFC) based on published gating strategies $[39,40]$. Cells were first incubated with a Zombie dye for $15 \mathrm{~min}$ at room temperature to detect dying cells. Cells were then washed with PBS $+2 \%$ FBS (FACS wash). Next, cells were incubated with Fc block (BD Biosciences) for $15 \mathrm{~min}$ at $4{ }^{\circ} \mathrm{C}$ and washed with FACS wash. Surface staining was performed with an antibody cocktail consisting of fluorescent antibodies against cell surface proteins. Cells were stained for $25 \mathrm{~min}$ in the dark at $4{ }^{\circ} \mathrm{C}$, and unbound antibodies were washed out by centrifugation. Lastly, cells were fixed with $1 \%$ paraformaldehyde prior to acquisition on a Symphony X50 flow cytometer (BD Biosciences), and data were analyzed using Flowjo software (BD Biosciences). All events from each stained sample were acquired by flow cytometry.

The antibodies and viability dyes used for the broad spectrum immune cell panel and $\mathrm{T}$ cell panel are listed in Tables 1 and 2, respectively. 
Table 1 Antibodies and dyes used for the broad spectrum immune cell panel

\begin{tabular}{|c|c|c|c|c|}
\hline \multicolumn{5}{|c|}{ Broad spectrum panel } \\
\hline Marker & Clone & Fluorophore & Dilution & Vendor \\
\hline Zombie viability dye & N/A & $n \mid R$ & $1: 100$ & Biolegend (San Diego, CA) \\
\hline CD3 & SK7 & AlexaFluor 700 & $1: 10$ & Biolegend \\
\hline CD14 & M5E2 & $\mathrm{PB}$ & $1: 10$ & BD Biosciences (San Jose, CA) \\
\hline CD16 & $3 \mathrm{G} 8$ & APC & $1: 10$ & Biolegend \\
\hline CD19 & HIB19 & PE-Cy5 & $1: 10$ & Biolegend \\
\hline CD45 & $\mathrm{HI} 30$ & PE & 1:10 & Sony (San Jose, CA) \\
\hline CD86 & FUN-1 & BV510 & $1: 20$ & BD Biosciences \\
\hline HLA-DR & L243 & BV605 & $1: 20$ & Biolegend \\
\hline
\end{tabular}

Table 2 Antibodies and dyes used for the T cell panel

\begin{tabular}{|c|c|c|c|c|}
\hline \multicolumn{5}{|l|}{ T cell panel } \\
\hline Marker & Clone & Fluorophore & Dilution & Vendor \\
\hline Zombie viability dye & N/A & Aqua & $1: 100$ & Biolegend (San Diego, CA) \\
\hline CD3 & SK7 & AlexaFluor 700 & $1: 20$ & Biolegend \\
\hline CD4 & SK3 & BUV805 & $1: 20$ & BD Biosciences (San Jose, CA) \\
\hline CD8 & SK1 & $\mathrm{APC}-\mathrm{Cy} 7$ & $1: 10$ & Biolegend \\
\hline CD14 & MOP9 & BUV395 & $1: 20$ & BD Biosciences \\
\hline CD25 & $2 \mathrm{~A} 3$ & BB515 & $1: 40$ & BD Biosciences \\
\hline CD38 & HIT2 & BV421 & $1: 20$ & Biolegend \\
\hline CD45 & $\mathrm{HI} 30$ & PE-Cy5 & $1: 20$ & Biolegend \\
\hline CD45RA & $\mathrm{HI} 100$ & PerCP-Cy5.5 & $1: 10$ & Biolegend \\
\hline CD127 & A019D5 & BV650 & $1: 20$ & Biolegend \\
\hline CCR4 & L291H4 & BV605 & $1: 20$ & Biolegend \\
\hline CCR6 & G034E3 & BV785 & $1: 20$ & Biolegend \\
\hline CCR7 & 150503 & PE-CF594 & $1: 20$ & BD Biosciences \\
\hline CCR10 & 314305 & APC & $1: 20$ & R\&D Systems (Minneapolis, MN) \\
\hline CXCR3 & $1 \mathrm{C} 6 / \mathrm{CXCR3}$ & $P E$ & $1: 2.5$ & BD Biosciences \\
\hline CXCR5 & $J 252 \mathrm{D} 4$ & $\mathrm{PE}-\mathrm{Cy} 7$ & $1: 78$ & Biolegend \\
\hline HLA-DR & G46-6 & BUV661 & $1: 313$ & BD Biosciences \\
\hline
\end{tabular}

\section{Statistical analyses}

Demographics (age and sex) and clinical characteristics (time from injury, medical diagnosis, and cause of injury) were described for each participant for both the broad spectrum immune panel and the $\mathrm{T}$ cell-specific panel. We used Shapiro-Wilk tests to assess the normality of all count, percentage, and normalized data. Due to some cell percentages and counts violating normality assumptions, non-parametric Wilcoxon signedrank tests were used to analyze differences between paired normal and injured knees for the broad panel cell counts and for the $\mathrm{T}$ cell panel normalized data. For the $\mathrm{T}$ cell-specific panel, CD3 cell counts were normalized to the leukocyte (CD45) count in the same knee, capturing the proportion of CD3 cells per all viable immune cells. In order to ensure enough cells for subsequent analyses in the $\mathrm{T}$ cell panel, a $\mathrm{T}$ cell (CD3) count threshold was set at 500 cells. A Fisher's exact test was used to assess the frequency of a $\mathrm{T}$ cell count greater than 500 cells in both the normal and injured knee synovial fluid samples. Non-parametric one-way ANOVAs and Mann-Whitney-Wilcoxon post hoc tests were used for the injured only to determine differences in $\mathrm{T}$ cell percentage, age, and time from injury comparisons across injury types. All statistical analyses were performed using JMP (SAS Institute Inc., Cary, NC). Significance was set at an alpha of $p<0.05$. 


\section{Results}

Assessment of immune cell subsets in the synovial fluid Using a broad spectrum immune cell flow cytometry panel, we analyzed synovial fluid from 10 subjects (mean age: $25.0 \pm 4.6$ years). Of these subjects, 3 had isolated meniscal tears, 5 had isolated ACL tears, and 2 had concomitant ACL+meniscus tears. Subject demographics are listed in Table 3. Figure 1 shows a representative gating scheme for the broad spectrum analysis. Within the synovial fluid, we were able to detect innate and adaptive immune cells, including $\mathrm{B}$ cells, $\mathrm{T}$ cells, monocytes, dendritic cells, and natural killer (NK) cells. Total viable cells were significantly increased in the injured knees as compared to the normal knees (Fig. 2, $p<0.05$ ).

Table 3 Demographics of subjects evaluated with the broad spectrum immune panel

\begin{tabular}{lllll}
\hline \multicolumn{4}{l}{ Broad spectrum panel subject demographics } \\
\hline Sex & Age & Time from injury & Diagnosis & Cause of injury \\
\hline F & 22 & 3 years & Meniscus & Snowboarding \\
M & 20 & 23 days & ACL+meniscus & Soccer \\
M & 32 & 51 days & Meniscus & Treadmill running \\
F & 18 & 52 days & ACL & Soccer \\
F & 30 & 6 years & Meniscus & Non-specific \\
M & 21 & 455 days & ACL & Soccer \\
M & 27 & 91 days & ACL & "Jumping in a mosh pit" \\
F & 28 & 53 days & ACL & Soccer \\
M & 25 & 38 days & $\mathrm{ACL}$ & Basketball \\
M & 27 & 37 days & $\mathrm{ACL}+$ meniscus & Frisbee golf
\end{tabular}

However, there was no significant difference in the percentage of viable cells in the normal (median: 99.5\%) and injured knees (median: 99.5\%). In comparison to normal knees, the median number of leukocytes (CD45) was elevated nearly 4-fold in the injured synovial fluid (Fig. 2, $p=0.06)$. $\mathrm{T}$ cells (CD3) were significantly increased in the injured knees $(p<0.05)$. While not statistically significant, on average there were higher numbers of NK cells $(p=0.08)$, neutrophils $(p=1.0)$, pre-monocytes $(p$ $=0.11)$, monocytes $(p=0.49)$, classical monocytes $(p=$ $0.57)$, intermediate monocytes $(p=0.28)$, and activated monocytes $(p=0.19)$ detected in the synovial fluid of injured knees than the normal knees. Based on the significant difference in the number of $\mathrm{T}$ cells between normal and injured knees and the large percentage of $\mathrm{T}$ cells in the joints (Fig. 1B), we focused subsequent analyses on immune profiling subsets within the $\mathrm{T}$ cell population.

\section{Delineation of synovial fluid T cell subsets}

In a separate group of 19 subjects (mean age: $33.7 \pm 11.1$ years) with ACL and/or meniscus tears (Table 4), we focused our analysis on identifying $\mathrm{T}$ cell subsets that are recruited to the synovial fluid following knee injury. Of these subjects, there were 11 isolated meniscal tears, 5 isolated ACL tears, and 3 concomitant ACL+meniscus tears. Figure 3 shows a representative gating scheme for the $\mathrm{T}$ cell profiling analysis. In order to ensure enough cells for subsequent analyses, a $\mathrm{T}$ cell (CD3) count threshold was set to 500 cells. For normal knee synovial fluid samples, only 4 out of 19 samples had more than 500 T cells, while 17 of 19 injured synovial fluid samples met this threshold. Overall a significantly lower percentage

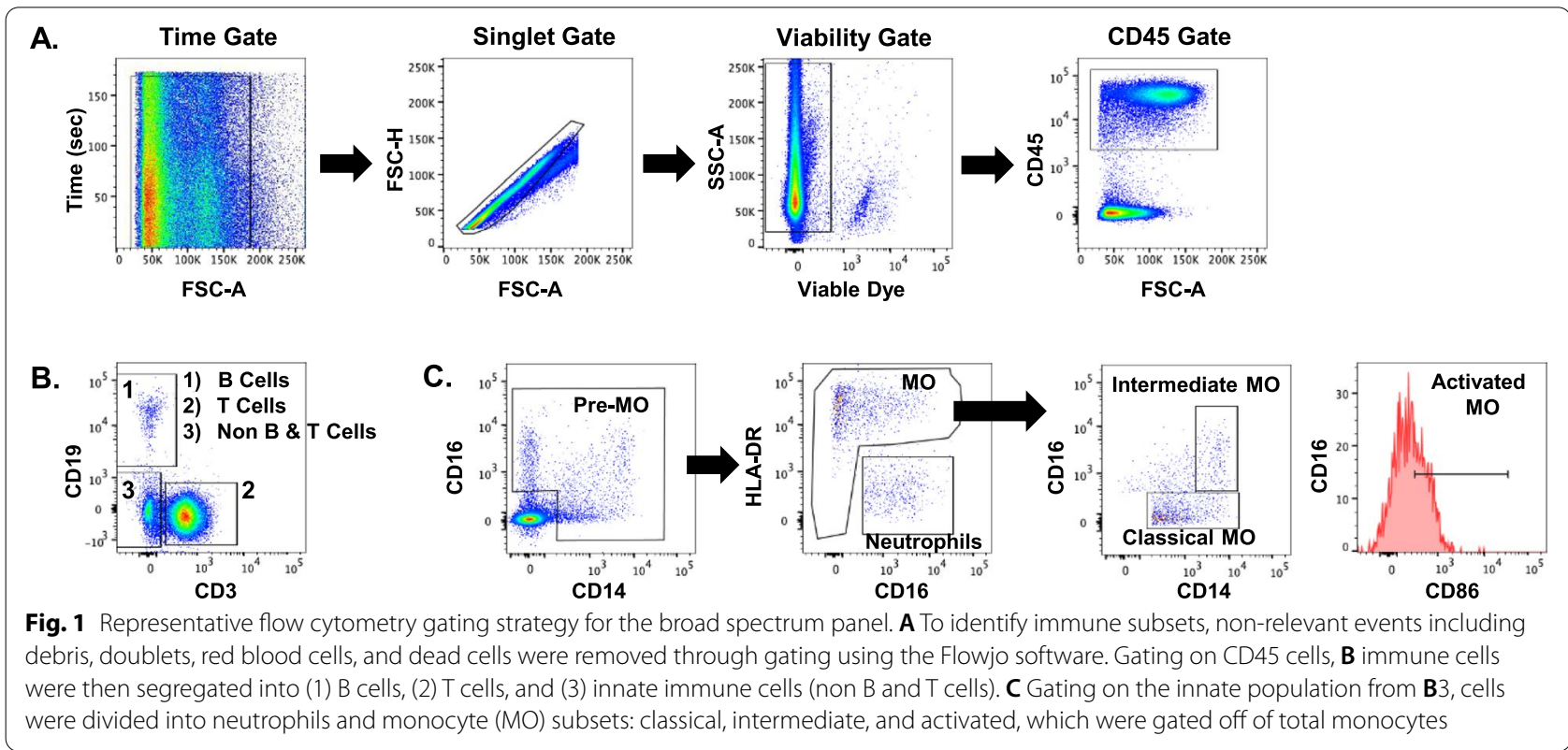




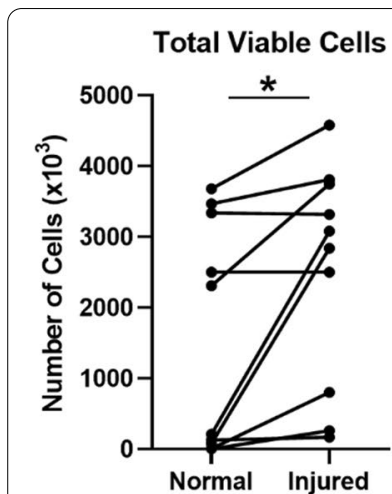

NK Cells

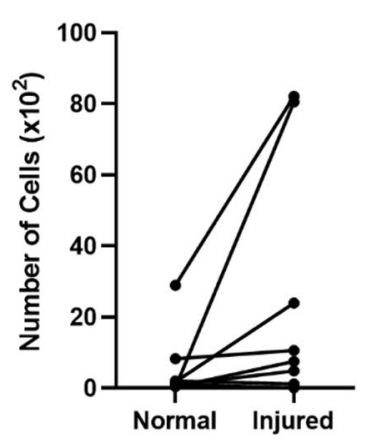

Classical Monocytes

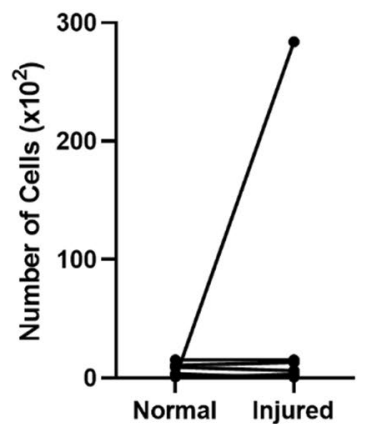

Leukocytes

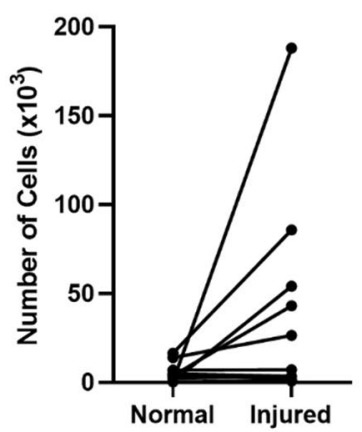

Neutrophils

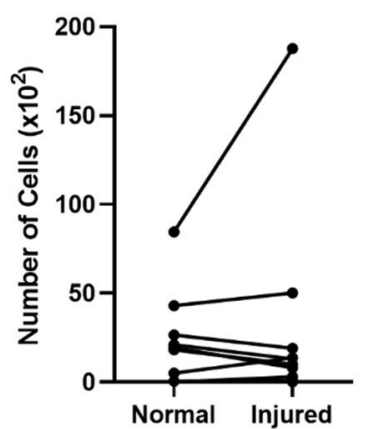

Intermediate Monocytes

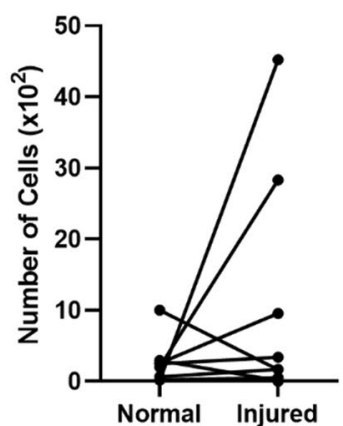

T Cells

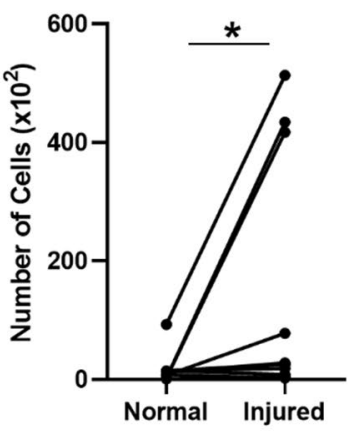

Pre Monocytes

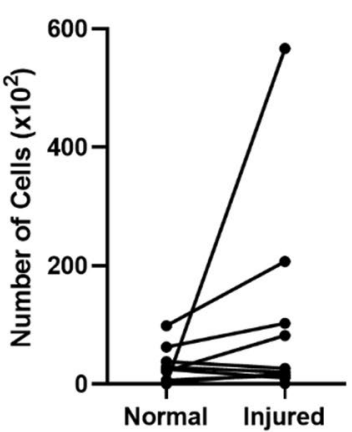

Activated Monocytes

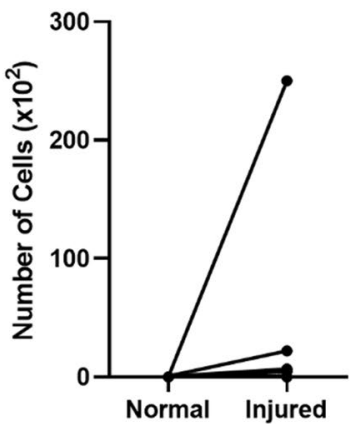

Fig. 2 Broad spectrum immune panel cell counts in the aspirated synovial fluid of normal and injured knees. Individual data points for each patient are presented with lines between paired samples $(N=10) .{ }^{*} p<0.05$

of normal knees $(21 \%)$ met this threshold compared to injured knees (89\%) (Table 5, $p<0.0001$ ). To account for dilution effects from the normal saline lavage during aspiration, we normalized the $\mathrm{T}$ cell count (CD3) to total leukocytes (CD45). Normalized $\mathrm{T}$ cell counts were also significantly increased in injured knees as compared to normal knees (Fig. 4, $p<0.05$ ).

Among the 17 injured samples that met the $\mathrm{T}$ cell threshold, a significant difference in age was detected between injury groups $(p=0.047)$. In particular, there was a significant difference in age when comparing the concomitant $\mathrm{ACL}+$ meniscus group (19 years) to the isolated ACL (36 years, $p<0.05$ ) and isolated meniscus (35 years, $p<0.05)$ groups. No significant differences were detected in the time from injury to surgery among injury groups. In-depth analysis of $\mathrm{T}$ cells revealed a heterogeneity of $\mathrm{T}$ cell subsets within the synovial fluid of both ACL- and meniscus-injured knees (Fig. 3). The majority of the CD4 and CD8 T cells were effector-memory cells based on their maturation profile (Fig. 3B). Using a 
Table 4 Demographics of subjects analyzed with the $T$ cellspecific panel

\begin{tabular}{lllll}
\hline \multicolumn{5}{l}{ T cell panel subject demographics } \\
\hline Sex & Age & Time from injury & Diagnosis & Cause of injury \\
\hline F & 40 & 3 months & ACL & Slipped on wet floor \\
M & 19 & 6 weeks & ACL+meniscus & Football \\
F & 49 & 1 month & ACL & Football \\
M & 28 & 4 months & ACL & Soccer \\
F & 34 & 3 months & ACL & Running \\
M & 20 & 3 months & ACL+meniscus & Basketball \\
F & 18 & 1 month & ACL+meniscus & Basketball \\
M & 30 & 2 months & ACL & Soccer \\
M & 37 & 2 months & Meniscus & Non-specific \\
M & 53 & 2 months & Meniscus & Non-specific \\
M & 48 & 6 months & Meniscus & Non-specific \\
M & 43 & chronic & Meniscus & Non-specific \\
F & 39 & 1 year & Meniscus & Non-specific \\
M & 45 & 5 months & Meniscus & Soccer \\
M & 27 & 4 months & Meniscus & Running \\
F & 21 & 6 months & Meniscus & Soccer \\
F & 34 & 1 year & Meniscus & Running \\
M & 19 & 1 month & Meniscus & Running \\
M & 36 & 1 year & Meniscus & Non-specific \\
\hline
\end{tabular}

combination of chemokine receptors, CD4 $\mathrm{T}$ cells (also known as $\mathrm{T}$ helper cells) were broken down into $\mathrm{T}$ helper subsets: Th1, Th2, Th9, Th17, Th22, ThGM-CSF, follicular helper cells (Tfh), and regulatory T cells (Tregs) (Fig. 5A). When analyzed by injury type, a significant difference in the overall percentage of CD4 T cells was detected $(p=$ 0.042), with ACL-injured knees having a higher percentage of CD4 T cells than ACL+meniscus-injured knees. No significant differences were detected among injury types for $\mathrm{T}$ helper subsets. However, among these subsets, Th1, Th2, and Th17 were on average higher in the injured knees. The injured synovial fluid samples also contained CD8 $\mathrm{T}$ cells (also known as cytotoxic T cells) and the following subsets of CD8 $\mathrm{T}$ cells: $\mathrm{T}$ effector memory (Tem) 1, Tem2, and Tem3 (Fig. 5B). However, there were no significant differences in the CD8 $\mathrm{T}$ cell subsets by injury type.

\section{Discussion}

The overall goal of the present study was to identify the major immune cell subsets in the synovial fluid of patients with ACL and/or meniscus injuries. Notably, more immune cells were found in injured knees compared to their paired normal knees. In our initial studies surveying innate and adaptive cell subsets in ACL- and meniscus-injured knees, we observed that $\mathrm{T}$ cells were elevated in the injured knees. Within the injured knees, we were able to differentiate CD4 and CD8 T cells into subsets and detected a significantly higher percentage of CD4 T cells in ACL- than ACL+meniscus-injured knees. However, we did not detect significant differences in $\mathrm{T}$ cell subsets across injury type. Collectively, our results provide foundational data showing that $\mathrm{ACL}$ and meniscus injury induce an immune cell-rich microenvironment that is heterogeneous, consisting primarily of $\mathrm{T}$ cells with multiple Th phenotypes. These phenotypes are similar to Th cells found in subjects with advanced OA and RA [33, 35, 41], suggesting that these immune cells may be important mediators of joint changes after ACL and meniscus injuries that contribute to PTOA development.

In the broad immune cell panel, we observed statistically significant increases in total viable cells and $\mathrm{T}$ cells in the injured knees. Additionally, while not statistically significant, we observed greater median counts in the injured knees for all immune cell types, except B cells and neutrophils. In this study, we hypothesized that immune cells would be elevated following ACL and meniscus injury based on previous studies of symptomatic knee OA [22]. In particular, prior work has shown increased macrophages and monocytes in patients with symptomatic OA [22]. Monocytes and macrophages can produce MIP-1, interferon (IFN)- $\gamma$, IL- $1 \beta$, and MMPs, which have been shown to be increased after ACL $[21,28]$ and meniscus injuries $[20,23,28]$. However, in the present study, we found significant increases in T cells in ACLand meniscus-injured subjects. In the inflamed synovium of RA patients, $\mathrm{T}$ cells in close proximity to macrophages induce cytokine production [42] either via direct cell interactions [43] or through the production of cytokines, such as IL-17 and IFN- $\gamma$ [44]. While prior studies have not definitively established $\mathrm{T}$ cells as mediators of OA $[45,46]$, both IL-17 [41] and IFN- $\gamma$ [47] are known to stimulate other cells, cytokines, and chemokines that lead to inflammation and destruction of bone and cartilage. To this point, in an ACL transection mouse model of $\mathrm{OA}, \mathrm{CD} 4 \mathrm{~T}$ cells increased early after injury and induced MIP-1Y production in the synovium, causing more cartilage degeneration [48]. Thus, our findings along with previous studies [41-48] suggest that the rise in T cells may occur downstream of increases in monocytes and macrophages. However, collection of synovial fluid at additional time points will be necessary to fully characterize the time course of immune cell changes following joint injury. Additionally, future studies investigating the relationship between macrophages, monocytes, and $\mathrm{T}$ cells may provide an enhanced understanding of the pathophysiology of PTOA following joint injury.

Our findings represent a snapshot of the immune cell profile in the synovial fluid of the joint. Different joint tissues, such as the synovium, cartilage, and menisci, may 


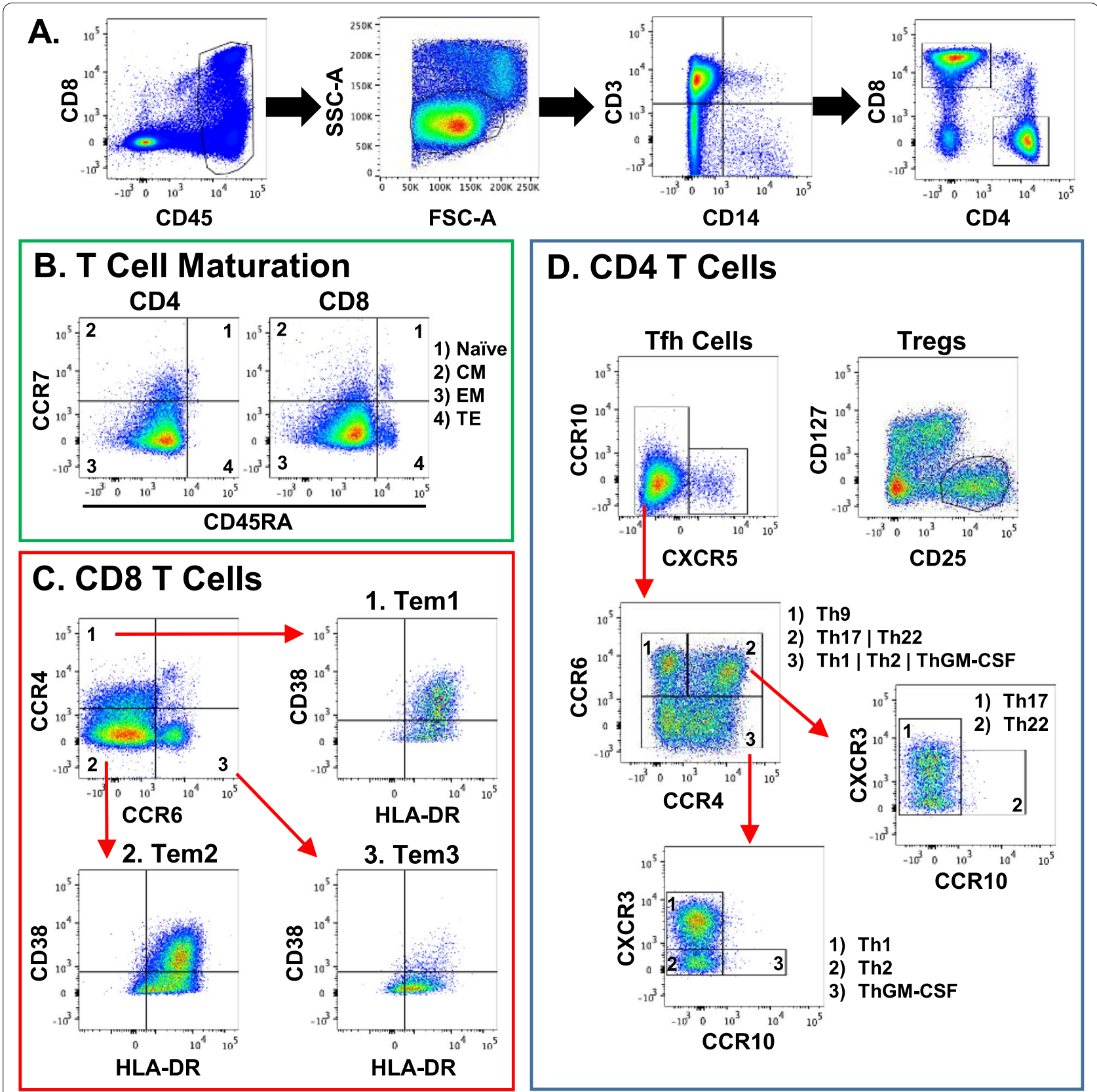

Fig. 3 Immune profiling synovial fluid-derived CD4 and CD8 T cells. A Gating strategy to exclude debris, dead cells, and non-CD3 T cells to visualize CD4 and CD8 T cells. B Maturation profile of CD4 and CD8 T cells in the synovial fluid (CM: central memory, EM: effector memory, TE: terminal effectors). C Division of activated CD8 T cells into Tem1, Tem2, and Tem3 subsets. D Visualization of differentiated CD4 Th subsets using chemokine receptors. The high dimensional panel identifies Th1, Th2, Th9, Th17, Th22, ThGM-CSF, Tfh, and Treg subsets

have different immune cell profiles. For example, among human subjects with acute articular ankle fracture, ankle $\mathrm{OA}$, and knee OA, there was an increase in macrophages in the synovium of acute articular ankle fracture subjects [49]. Also, in the synovium of dogs with cranial cruciate ligament tears, CD4, CD8, and non-CD4/CD8 $\mathrm{T}$ cells were increased compared to healthy dogs [50].
Furthermore, in menisci of human subjects with RA and OA, immunohistochemistry showed that macrophages, $\mathrm{T}$ cells, and B cells were increased in the outer, vascular region compared to the less vascular, central region of the tissue [51]. Similarly, a study investigating macrophages and $\mathrm{T}$ cells in a mouse model of ACL transection found increased staining of macrophages and $\mathrm{T}$ cells in the 
Table 5 Contingency table of synovial fluid samples meeting the $T$ cell threshold (Fisher's exact test $\left(2\right.$-tail): $\left.{ }^{*} p<0.0001\right)$

\begin{tabular}{llll}
\hline T cells $\geq \mathbf{5 0 0}$ & & & Total \\
\hline & No & Yes & 19 \\
\hline Normal & 15 & 4 & 19 \\
Injured & 2 & 17 & 38 \\
Total & 17 & 21 & \\
\hline
\end{tabular}

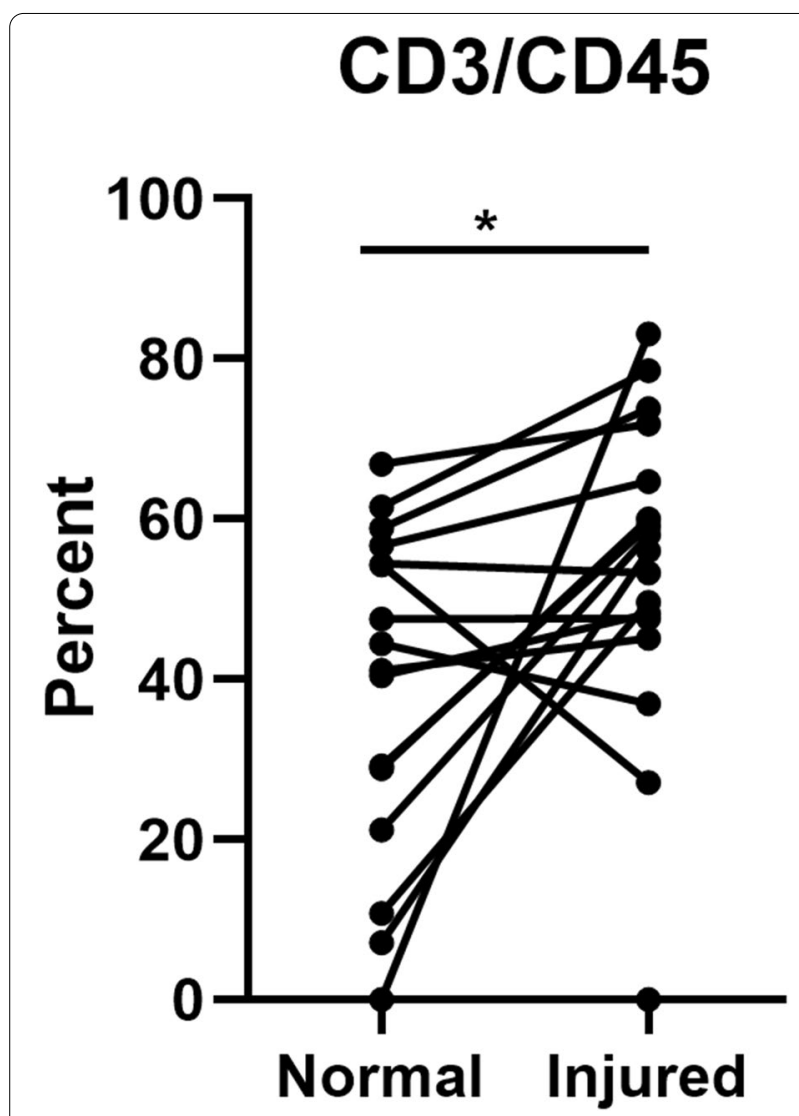

Fig. 4 T cells (CD3) normalized to leukocytes (CD45) using the T cell-specific panel $(N=17)$. Individual data points for each patient are presented with lines between paired samples. ${ }^{*} p<0.05$

vascularized region of the menisci [52]. These increases in specific immune cells of different tissues indicate the importance of localized profiling of cell types to study progression of PTOA.
The overall percentage of CD4 $\mathrm{T}$ cells differed significantly among injury types, with ACL+meniscus and ACL groups having the lowest and highest percentages, respectively. Prior work has shown that there is an increase in the number of CD4 $\mathrm{T}$ regulatory cells that occurs with aging [53]. Therefore, the significant difference in CD4 $\mathrm{T}$ cells between the concomitant $\mathrm{ACL}+$ meniscus and isolated $\mathrm{ACL}$ and meniscus groups could be due to age. However, a variety of factors, such as age, sex, and time from injury, may influence these results as well. Investigation of these factors as potential confounders or moderators was beyond the scope of this pilot study. Therefore, future larger scale studies will be necessary to investigate the effect of these variables on synovial fluid immune cell profiles following joint injury.

Of the CD4 subsets, Th1, Th2, and Th17 were the dominant populations present in the injured synovial fluid. Similarly, Lurati et al. [33] analyzed blood samples from RA, OA, and healthy subjects. They found that RA samples had the highest percentage of both CD4 T cells and Th17 cells followed by OA samples. However, there were no differences in Th1 or Th2 cell percentages between subject groups. Th17 cells produce IL-17, which causes synovial fibroblasts, chondrocytes, macrophages, and osteoclasts to elicit a cascade that promotes inflammation, cartilage degradation, and changes in bone metabolism [41]. Additionally, Rosshirt et al. also found higher numbers of CD4 $\mathrm{T}$ cells, favoring Th1 cell activation, in the synovial fluid of end-stage OA subjects compared to their peripheral blood, indicating localized joint inflammation [35]. Yang et al. also found that CCR4+CCR6+ Th cells (encompasses Th17 and Th22 cells) are directly correlated with anterior knee laxity in ACL-reconstructed human subjects [54]. Prior work has shown that naïve $\mathrm{T}$ cells can be differentiated into Th1 or Th17 cells by senescent cells, which are involved in age-related primary OA [53]. Recently, PTOA following tibial plateau fracture was found to be more advanced in $\mathrm{T}$-cell deficient mice than in control mice [55]. The $\mathrm{T}$ cell deficiency eliminates all $\mathrm{T}$ cell subsets, both inflammatory and regulatory, and it is currently unknown whether the increased PTOA is due to a lack of regulatory $\mathrm{T}$ cells. Our results demonstrate the presence of regulatory $\mathrm{T}$ cells in the synovial fluid that can modulate inflammation. As well, the present study included ACL and meniscus injuries, while other joint injuries may lead to different immune cell profiles. Thus, there is a need to further profile-specific

(See figure on next page.)

Fig. 5 T cell panel results by injury type. A CD4 T cells and CD4 subset (Tfh, Treg, Th1, Th2, ThGM-CSF, Th9, Th17, and Th22) frequencies (individual data points and median) in the synovial fluid of injured knees. A statistically significant difference was detected in the percentage of CD4 T cells between $A C L$-injured and $A C L+$ meniscus-injured knees ( ${ }^{*} p=0.042$ ). B CD8 T cells and CD8 subset (Tem1, Tem2, and Tem3) frequencies in the synovial fluid of injured knees. No statistically significant differences were detected $(p>0.05)(N=17$ injured samples with 500 or more T cells) 


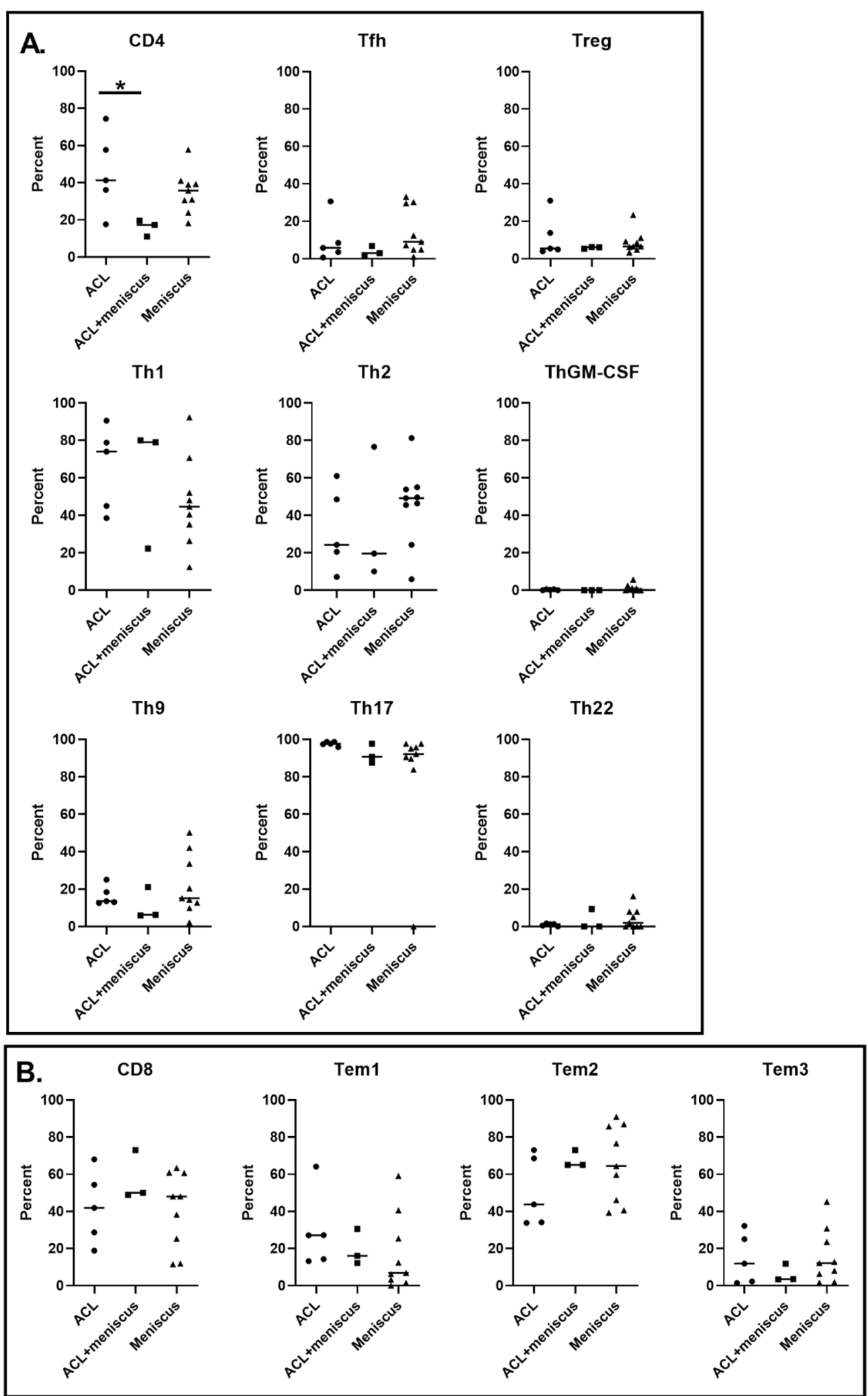

Fig. 5 (See legend on previous page.) 
phenotypes of PTOA in addition to different types of arthritis.

With regard to CD8 $\mathrm{T}$ cells, there is limited in vivo human data characterizing their profile following joint injury. In a previous animal study, OA was induced via ACL transection causing increased activation of CD8 T cells and elevated tissue inhibitor of metalloproteinase-1 in the synovium and splenocytes, which correlated with increased cartilage degeneration [56]. In RA, there have been a few studies showing that an increased apoptoticepitope of CD8 T cells was predictive of non-responsiveness to anti-TNF-a therapies [57]. Additionally, in synovial fluid, effector memory CD8 T cells were found to be increased in RA subjects compared to healthy controls [58]. Given that similar T helper cells and CD8 T cells are found in subjects with more advanced OA and RA, our findings suggest that these cells present after ACL and meniscus injuries may be contributing to the development of PTOA. Furthermore, the similar profiles of CD4 and CD8 subsets following these knee injuries are consistent with the similar phenotype of PTOA following meniscus and ACL injuries. On the other hand, this was a pilot study and may not be powered to detect differences by injury type. In addition, this study included patients with a wide range of time from injury to knee surgery; therefore, in future larger scale studies, it will be important to investigate the time course of $\mathrm{T}$ cell profiles after $\mathrm{ACL}$ and meniscus injuries.

\section{Conclusion}

In conclusion, at the time of surgery, the localized synovial fluid immune response following ACL and meniscus injuries shows a $\mathrm{T}$ cell-predominant immune profile in ACL, meniscus, and ACL+meniscus-injured knees. Among these injured knees, the percentage of CD4 $\mathrm{T}$ cells was significantly higher in the ACL- than the $\mathrm{ACL}+$ meniscus-injured knees. While there were no detectable differences in $\mathrm{T}$ cell subsets by injury type, Th1 and Th17 activation was favored among the CD4 T cells, which is supported by their active roles in OA. Overall, the findings of the present study describe both broad and $\mathrm{T}$ cell-specific immune profiles of human synovial fluid from ACL and/or meniscus-injured and normal knees. Future studies will focus on longitudinal studies to better understand the kinetics of $\mathrm{T}$ cell differentiation and effector function in relation to the development of PTOA.

\section{Abbreviations}

ACL: Anterior cruciate ligament; COMP: Cartilage oligomeric matrix protein; IFN: Interferon; IL: Interleukin; MIP: Macrophage inhibitory protein; MMP: Matrix metalloproteinases; NK: Natural killer cells; PFC: Polychromatic flow cytometry; PGE2: Prostaglandin E2; PTOA: Post-traumatic osteoarthritis; OA Osteoarthritis; RA: Rheumatoid arthritis; Tfh: T follicular helper cells; TNF: Tumor necrosis factor; Tregs: Regulatory T cells.

\section{Acknowledgements}

We would like to acknowledge the clinical research staff who assisted in recruitment, consenting subjects, and collecting samples: Elizabeth Pennington, RN, Suzanne Finley, RN, and Anne Boyd. We would also like to thank Lucas Lyons and Ben Andress for assisting with synovial fluid processing after collection. Last, we would like to thank Dean Taylor, MD, Anunziato Amendola, MD, Jonathan Riboh, MD, and William Garrett, MD, PhD for contributing samples to the study.

\section{Authors' contributions}

JW, JY, SK, LD, and AM conceived and designed the study. JW, BL, and AT provided potential subjects for this study. JW and SD recruited and consented these subjects. SK, AH, and SD collected samples from the subjects. SK and AH processed synovial fluid immediately upon collection. AH, AB, and JY stained samples for flow cytometry. $A B$ and JY acquired and analyzed raw flow data. $\mathrm{SK}, \mathrm{AH}, \mathrm{AB}, \mathrm{LD}, \mathrm{AM}, J \mathrm{~J}$, and $\mathrm{AG}$ statistically analyzed and interpreted the results. SK and $A H$ drafted the manuscript. All authors read and approved the final manuscript.

\section{Funding}

We would like to thank the $\mathrm{NIH}$ for funding from the following grants AR065527, AR074800, AR075399, AR073221, AR079184, and an Orthopaedic Research and Education Foundation grant with funding provided by the Musculoskeletal Transplant Foundation.

Availability of data and materials

Data generated and analyzed during this study are available from the corresponding author on reasonable request.

\section{Declarations}

Ethics approval and consent to participate

This study received approval (Pro00070197) from the Institutional Review Board at Duke University School of Medicine. All subjects were consented prior to participation in this study.

\section{Consent for publication \\ $\mathrm{N} / \mathrm{A}$}

\section{Competing interests}

The authors declare that they have no competing interests. JW has received education payments from Prodigy Surgical, nonconsulting fees from Arthrex, and hospitality payments from Aesculap Biologics. AT has received non-consulting fees from Vericel Corporation, hospitality payments from Smith+Nephew, Incorporation, Vericel Corporation, Flexion Therapeutics, and Trice Medical. BL has received education payments from Smith+Nephew and SouthTech Orthopedics and hospitality payments from Wright Medical Technology, Crossroads Extremity Systems, and Stryker Corporation.

\section{Author details}

${ }^{1}$ Department of Biomedical Engineering, Duke University, Durham, NC, USA. ${ }^{2}$ Department of Orthopaedic Surgery, Duke University School of Medicine, Durham, NC, USA. ${ }^{3}$ Department of Surgery, Duke University School of Medicine, Durham, NC, USA. ${ }^{4}$ Department of Mechanical Engineering and Materials Science, Duke University, Durham, NC, USA. ${ }^{5}$ Department of Pathology, Duke University School of Medicine, Durham, NC, USA.

Received: 24 February 2021 Accepted: 17 October 2021

Published online: 04 November 2021

\section{References}

1. Lohmander LS, Englund PM, Dahl LL, Roos EM. The long-term consequence of anterior cruciate ligament and meniscus injuries: osteoarthritis. Am J Sports Med. 2007;35(10):1756-69.

2. Kibler WB. Orthopaedic knowledge update: sports medicine 4, 4th edition edn: American Academy of Orthopaedic; 2009.

3. Steiner CA, Barrett ML, Weiss AJ, Andrews RM. Trends and projections in hospital stays for adults with multiple chronic conditions, 2003-2014: 
Statistical Brief \#183. In: Healthcare Cost and Utilization Project (HCUP) Statistical Briefs. Rockville; 2014.

4. Andriacchi TP, Briant PL, Bevill SL, Koo S. Rotational changes at the knee after ACL injury cause cartilage thinning. Clin Orthop Relat Res. 2006:442:39-44.

5. Fithian DC, Paxton LW, Goltz DH. Fate of the anterior cruciate ligamentinjured knee. Orthop Clin North Am. 2002;33(4):621-36 v.

6. Roos H, Adalberth T, Dahlberg L, Lohmander LS. Osteoarthritis of the knee after injury to the anterior cruciate ligament or meniscus: the influence of time and age. Osteoarthritis Cartilage. 1995;3(4):261-7.

7. Stiebel M, Miller LE, Block JE. Post-traumatic knee osteoarthritis in the young patient: therapeutic dilemmas and emerging technologies. Open Access J Sports Med. 2014:5:73-9.

8. Georgoulis AD, Papadonikolakis A, Papageorgiou CD, Mitsou A, Stergiou $N$. Three-dimensional tibiofemoral kinematics of the anterior cruciate ligament-deficient and reconstructed knee during walking. Am J Sports Med. 2003;31(1):75-9.

9. Hofbauer M, Thorhauer ED, Abebe E, Bey M, Tashman S. Altered tibiofemoral kinematics in the affected knee and compensatory changes in the contralateral knee after anterior cruciate ligament reconstruction. Am J Sports Med. 2014;42(11):2715-21.

10. Papannagari R, Gill TJ, Defrate LE, Moses JM, Petruska AJ, Li G. In vivo kinematics of the knee after anterior cruciate ligament reconstruction: a clinical and functional evaluation. Am J Sports Med. 2006;34(12):2006-12.

11. Sutter EG, Liu B, Utturkar GM, Widmyer MR, Spritzer CE, Cutcliffe HC, et al. Effects of anterior cruciate ligament deficiency on tibiofemoral cartilage thickness and strains in response to hopping. Am J Sports Med. 2019;47(1):96-103.

12. Tashman S, Kolowich P, Collon D, Anderson K, Anderst W. Dynamic function of the ACL-reconstructed knee during running. Clin Orthop Relat Res. 2007:454:66-73.

13. Crook BS, Collins AT, Lad NK, Spritzer CE, Wittstein JR, DeFrate LE. Effect of walking on in vivo tibiofemoral cartilage strain in $\mathrm{ACL}$-deficient versus intact knees. J Biomech. 2021;116.

14. Allaire R, Muriuki M, Gilbertson L, Harner CD. Biomechanical consequences of a tear of the posterior root of the medial meniscus. Similar to total meniscectomy. J Bone Joint Surg Am. 2008;90(9):1922-31.

15. Bedi A, Kelly NH, Baad M, Fox AJ, Brophy RH, Warren RF, et al. Dynamic contact mechanics of the medial meniscus as a function of radial tear, repair, and partial meniscectomy. J Bone Joint Surg Am. 2010;92(6):1398-408.

16. Carter TE, Taylor KA, Spritzer CE, Utturkar GM, Taylor DC, Moorman CT 3rd, et al. In vivo cartilage strain increases following medial meniscal tear and correlates with synovial fluid matrix metalloproteinase activity. J Biomech. 2015;48(8):1461-8.

17. Maher SA, Wang H, Koff MF, Belkin N, Potter HG, Rodeo SA. Clinical platform for understanding the relationship between joint contact mechanics and articular cartilage changes after meniscal surgery. J Orthop Res. 2017:35(3):600-11.

18. Rao AJ, Erickson BJ, Cvetanovich GL, Yanke AB, Bach BR Jr, Cole BJ. The meniscus-deficient knee: biomechanics, evaluation, and treatment options. Orthop J Sports Med. 2015;3(10):2325967115611386.

19. Amano K, Huebner JL, Stabler TV, Tanaka M, McCulloch CE, Lobach I, et al. Synovial fluid profile at the time of anterior cruciate ligament reconstruction and its association with cartilage matrix composition 3 years after surgery. Am J Sports Med. 2018;46(4):890-9.

20. Clair AJ, Kingery MT, Anil U, Kenny L, Kirsch T, Strauss EJ. Alterations in synovial fluid biomarker levels in knees with meniscal injury as compared with asymptomatic contralateral knees. Am J Sports Med. 2019:47(4):847-56.

21. Kaplan DJ, Cuellar VG, Jazrawi LM, Strauss EJ. Biomarker Changes in anterior cruciate ligament-deficient knees compared with healthy controls. Arthroscopy. 2017;33(5):1053-61.

22. Kraus VB, MCDaniel G, Huebner UL, Stabler TV, Pieper CF, Shipes SW, et al. Direct in vivo evidence of activated macrophages in human osteoarthritis. Osteoarthritis Cartilage. 2016:24(9):1613-21.

23. Liu B, Goode AP, Carter TE, Utturkar GM, Huebner JL, Taylor DC, et al. Matrix metalloproteinase activity and prostaglandin E2 are elevated in the synovial fluid of meniscus tear patients. Connect Tissue Res. 2017;58(3-4):305-16.
24. Rai MF, McNulty AL. Meniscus beyond mechanics: using biology to advance our understanding of meniscus injury and treatment. Connect Tissue Res. 2017:58(3-4):221-4.

25. Elsaid KA, Machan JT, Waller K, Fleming BC, Jay GD. The impact of anterior cruciate ligament injury on lubricin metabolism and the effect of inhibiting tumor necrosis factor alpha on chondroprotection in an animal model. Arthritis Rheum. 2009:60(10):2997-3006.

26. Hayward AL, Deehan DJ, Aspden RM, Sutherland AG. Analysis of sequential cytokine release after $\mathrm{ACL}$ reconstruction. Knee Surg Sports Traumatol Arthrosc. 2011;19(10):1709-15.

27. Lohmander LS, Saxne T, Heinegard DK. Release of cartilage oligomeric matrix protein (COMP) into joint fluid after knee injury and in osteoarthritis. Ann Rheum Dis. 1994;53(1):8-13.

28. Cuellar VG, Cuellar JM, Kirsch T, Strauss EJ. Correlation of synovial fluid biomarkers with cartilage pathology and associated outcomes in knee arthroscopy. Arthroscopy. 2016;32(3):475-85.

29. Rowe MA, Harper LR, McNulty MA, Lau AG, Carlson CS, Leng L, et al. Reduced osteoarthritis severity in aged mice with deletion of macrophage migration inhibitory factor. Arthritis Rheumatol. 2017:69(2):352-61.

30. Sambamurthy N, Zhou C, Nguyen V, Smalley R, Hankenson KD, Dodge $G R$, et al. Deficiency of the pattern-recognition receptor CD14 protects against joint pathology and functional decline in a murine model of osteoarthritis. PLoS One. 2018;13(11):e0206217.

31. Kriegova E, Manukyan G, Mikulkova Z, Gabcova G, Kudelka M, Gajdos P, et al. Gender-related differences observed among immune cells in synovial fluid in knee osteoarthritis. Osteoarthritis Cartilage. 2018;26(9):1247-56.

32. LiYS, Luo W, Zhu SA, Lei GH. T cells in osteoarthritis: alterations and beyond. Front Immunol. 2017;8:356.

33. Lurati A, Laria A, Gatti A, Brando B, Scarpellini M. Different T cells' distribution and activation degree of Th17 CD4+ cells in peripheral blood in patients with osteoarthritis, rheumatoid arthritis, and healthy donors: preliminary results of the MAGENTA CLICAO study. Open Access Rheumatol. 2015;7:63-8.

34. Orlowsky EW, Kraus VB. The role of innate immunity in osteoarthritis: when our first line of defense goes on the offensive. J Rheumatol. 2015:42(3):363-71.

35. Rosshirt N, Hagmann S, Tripel E, Gotterbarm T, Kirsch J, Zeifang F, et al. A predominant Th1 polarization is present in synovial fluid of end-stage osteoarthritic knee joints: analysis of peripheral blood, synovial fluid and synovial membrane. Clin Exp Immunol. 2019;195(3):395-406.

36. Isomaki P, Luukkainen R, Lassila O, Toivanen P, Punnonen J. Synovial fluid T cells from patients with rheumatoid arthritis are refractory to the Thelper type 2 differentiation-inducing effects of interleukin-4. Immunology. 1999;96(3):358-64.

37. Pawlowska J, Mikosik A, Soroczynska-Cybula M, Jozwik A, Luczkiewicz P, Mazurkiewicz S, et al. Different distribution of CD4 and CD8 T cells in synovial membrane and peripheral blood of rheumatoid arthritis and osteoarthritis patients. Folia Histochem Cytobiol. 2009;47(4):627-32.

38. van Hamburg JP, Asmawidjaja PS, Davelaar N, Mus AM, Colin EM, Hazes $J M$, et al. Th17 cells, but not Th1 cells, from patients with early rheumatoid arthritis are potent inducers of matrix metalloproteinases and proinflammatory cytokines upon synovial fibroblast interaction, including autocrine interleukin-17A production. Arthritis Rheum. 2011;63(1):73-83.

39. Staser KW, Eades W, Choi J, Karpova D, DiPersio JF. OMIP-042: 21-color flow cytometry to comprehensively immunophenotype major lymphocyte and myeloid subsets in human peripheral blood. Cytometry A. 2018;93(2):186-9.

40. Ong SM, Teng K, Newell E, Chen H, Chen J, Loy T, et al. A novel, fivemarker alternative to CD16-CD14 gating to identify the three human monocyte subsets. Front Immunol. 2019;10:1761.

41. Koenders MI, Joosten LA, van den Berg WB. Potential new targets in arthritis therapy: interleukin (IL)-17 and its relation to tumour necrosis factor and IL-1 in experimental arthritis. Ann Rheum Dis. 2006;65(Suppl 3):iii29-33.

42. Sebbag M, Parry SL, Brennan FM, Feldmann M. Cytokine stimulation of T lymphocytes regulates their capacity to induce monocyte production of tumor necrosis factor-alpha, but not interleukin-10: possible relevance to pathophysiology of rheumatoid arthritis. Eur J Immunol. 1997:27(3):624-32. 
43. Wagner DH Jr, Stout RD, Suttles J. Role of the CD40-CD40 ligand interac tion in CD4+ T cell contact-dependent activation of monocyte interleukin-1 synthesis. Eur J Immunol. 1994;24(12):3148-54.

44. Aarvak T, Chabaud M, Miossec P, Natvig JB. IL-17 is produced by some proinflammatory Th1/Th0 cells but not by Th2 cells. J Immunol. 1999;162(3):1246-51.

45. Pelletier JP, Martel-Pelletier J, Abramson SB. Osteoarthritis, an inflammatory disease: potential implication for the selection of new therapeutic targets. Arthritis Rheum. 2001;44(6):1237-47.

46. Sakkas LI, Platsoucas CD. Role of T cells in the pathogenesis of osteoarthritis. Arthritis Rheum. 2002:46(11):3112-3.

47. Goldring MB, Sandell LJ, Stephenson ML, Krane SM. Immune interferon suppresses levels of procollagen mRNA and type II collagen synthesis in cultured human articular and costal chondrocytes. J Biol Chem. 1986;261(19):9049-55.

48. Shen PC, Wu CL, Jou IM, Lee CH, Juan HY, Lee PJ, et al. T helper cells promote disease progression of osteoarthritis by inducing macrophage inflammatory protein-1 gamma. Osteoarthritis Cartilage. 2011;19(6):728-36.

49. Furman BD, Kimmerling KA, Zura RD, Reilly RM, Zlowodzki MP, Huebner $J$, et al. Articular ankle fracture results in increased synovitis, synovial macrophage infiltration, and synovial fluid concentrations of inflammatory cytokines and chemokines. Arthritis Rheumatol. 2015;67(5):1234-9.

50. Muir P, Kelly JL, Marvel SJ, Heinrich DA, Schaefer SL, Manley PA, et al. Lymphocyte populations in joint tissues from dogs with inflammatory stifle arthritis and associated degenerative cranial cruciate ligament rupture. Vet Surg. 2011;40(6):753-61.

51. Fuhrmann IK, Steinhagen J, Ruther W, Schumacher U. Comparative immunohistochemical evaluation of the zonal distribution of extracellular matrix and inflammation markers in human meniscus in osteoarthritis and rheumatoid arthritis. Acta Histochem. 2015;117(3):243-54.
52. Xie J, Zhang D, Lin Y, Yuan Q, Zhou X. Anterior Cruciate ligament transection-induced cellular and extracellular events in menisci: implications for osteoarthritis. Am J Sports Med. 2018:46(5):1185-98.

53. Faust HJ, Zhang H, Han J, Wolf MT, Jeon OH, Sadtler K, et al. IL-17 and immunologically induced senescence regulate response to injury in osteoarthritis. J Clin Invest. 2020;130(10):5493-507.

54. Yang R, Zhang Z, Song B, Wang P, Wang L, Li W, et al. Ratio of T helper to regulatory $T$ cells in synovial fluid and postoperative joint laxity after allograft anterior cruciate ligament reconstruction. Transplantation. 2012;94(11):1160-6.

55. Buchanan MW, Furman BD, Zeitlin JH, Huebner JL, Kraus VB, Yi JS, et al. Degenerative joint changes following intra-articular fracture are more severe in mice with T cell deficiency. J Orthop Res. 2020.

56. Hsieh JL, Shiau AL, Lee CH, Yang SJ, Lee BO, Jou IM, et al. CD8+T cellinduced expression of tissue inhibitor of metalloproteinses-1 exacerbated osteoarthritis. Int J Mol Sci. 2013;14(10):19951-70.

57. Citro A, Scrivo R, Martini H, Martire C, De Marzio P, Vestri AR, et al. CD8+ T cells specific to apoptosis-associated antigens predict the response to tumor necrosis factor inhibitor therapy in rheumatoid arthritis. PLoS One. 2015;10(6):e0128607.

58. Cho BA, Sim JH, Park JA, Kim HW, Yoo WH, Lee SH, et al. Characterization of effector memory CD8+ T cells in the synovial fluid of rheumatoid arthritis. J Clin Immunol. 2012;32(4):709-20.

\section{Publisher's Note}

Springer Nature remains neutral with regard to jurisdictional claims in published maps and institutional affiliations.
Ready to submit your research? Choose BMC and benefit from:

- fast, convenient online submission

- thorough peer review by experienced researchers in your field

- rapid publication on acceptance

- support for research data, including large and complex data types

- gold Open Access which fosters wider collaboration and increased citations

- maximum visibility for your research: over $100 \mathrm{M}$ website views per year

At BMC, research is always in progress.

Learn more biomedcentral.com/submissions 